\title{
Insecticidal Activity of Essential Oil of Syzygium Aromaticum Flower in Drosophila
}

\author{
Mariam Ulfah ${ }^{1(\mathbb{D})}$, Mufidah Murdifin ${ }^{1 \mathbb{D}}$, Sukamto $S$ Mamada ${ }^{1 \mathbb{D}}$, Rudi Arfiansyah ${ }^{1}{ }^{\mathbb{D}}$, Tri Puspita \\ Roska $^{1}$ (D), Ahmed Rakib ${ }^{2}$ (D), Talha Bin Emran ${ }^{3}$ (D), Firzan Nainu 1,* (D) \\ 1 Faculty of Pharmacy, Universitas Hasanuddin, Makassar 90245, Indonesia \\ 2 Department of Pharmacy, Faculty of Biological Sciences, University of Chittagong, Chittagong 4331, Bangladesh \\ 3 Department of Pharmacy, BGC Trust University Bangladesh, Chittagong 4381, Bangladesh \\ * Correspondence: firzannainu@ unhas.ac.id (F.N.);
}

Received: 20.05.2021; Revised: 15.06.2021; Accepted: 18.06.2021; Published: 24.06.2021

\begin{abstract}
A comprehensive investigation regarding insecticides' mechanism of action on agricultureand medically-important insects is an important issue to consider. This study aimed to investigate the insecticidal activity of essential oil of Syzygium aromaticum flower (EOSF) using Drosophila melanogaster as an in vivo insect model platform. EOSF was used as a proof-of-concept natural product since it has been reported to exert insecticide activity on certain harmful insects. EOSF was prepared by the water distillation method, and the essential oil is then used to identify its effects on the mortality rate and the locomotor activity of Drosophila. Our results demonstrated that both males and females of D. melanogaster were succumbed immediately, in a dose-response manner, upon EOSF exposure. A slight discrepancy was evident in the effect of EOSF on the mortality rate of males compared to their females' counterparts, thus delineating the possible sex-dependent effect of EOSF on D. melanogaster. Further, decreased locomotor activity was observed on both male and female Drosophila upon EOSF exposure. Overall, it was concluded that EOSF (10 $\mu \mathrm{l}, 100 \mu \mathrm{l}$, and $1000 \mu \mathrm{l}$ concentrations) produced insecticidal activity in D. melanogaster.
\end{abstract}

Keywords: essential oil; Syzygium aromaticum; insecticidal; fruit fly; insecticide screening.

(c) 2021 by the authors. This article is an open-access article distributed under the terms and conditions of the Creative Commons Attribution (CC BY) license (https://creativecommons.org/licenses/by/4.0/).

\section{Introduction}

Insects are one of the largest and one of the most diverse invertebrates that can be found in all types of environments [1]. This group has been suggested to comprise more than twothirds of the total organisms present on Earth. Some insects, such as bees, butterflies, and ants, have been shown to have beneficial meanings in humans' life [2,3]. These insects play an important role in pollinating certain flowering plants, a process that is critical in the agriculture field [2]. However, many insects have been considered pests by humans as they can damage certain structures (for example, termites) or even transmit certain diseases to humans (for example, mosquitoes and flies) [4-6]. Horribly, some insects (such as locusts and weevils) sometimes lead to economic losses as they can cause heavy losses in agricultural products [7]. The use of insecticides is introduced as a popular approach to eradicate those pest insects $[8,9]$. In general, insecticides are formulated to exert their effects once entering insects' bodies and by doing so, they can kill one or more species of insects [8]. At present, synthetic insecticides are still familiar on the market because they can be applied easily in large areas, and the results can be felt quickly [8]. However, extensive and long-term exposure to synthetic insecticides 
has been reported to cause adverse effects to humans and ecosystems [8]. Moreover, their residues have been found in food, milk, water, soil, and other environments [10]. Therefore, several studies were developed to find chemical compounds from plants that can be used as alternative insecticides without harming animals and humans [11-13].

Currently, essential oils have been widely reported as one of the alternative insecticides $[14,15]$. The essential oil of Syzygium aromaticum flower (EOSF) is one of the essential oils obtained from the Myrtaceae family [16]. Eugenol, one of the components of EOSF, and its derivatives have been reported to yield insecticidal effects in vitro [17] and also on several insects such as Aedes aegypti [18], Sitophilus zeamais [19], and Reticulitermes speratus Kolbe [20]. Essential oils have been shown to exert multiple bioactivities, including as an insecticide, mosquito repellent, and oviposition agent to control various types of insects [6,15,21,22]. Essential oils can be obtained from suitable plant samples using the distillation method that is immersed in water and boiled by direct heating [23]. In addition, the use of EOSF has great advantages, such as mild side effects on non-targeted organisms and low persistence in the soil compared to insecticides on the market [24].

A detailed investigation regarding insecticides' mechanism of action on agriculture- and medically-important insects is one of the most important issues to consider nowadays [14,25]. However, due to limitations in the established procedures and inadequate availability of proper transgenic/mutant genotypes required for such experiments [26,27], this issue presents a huge hurdle to researchers from developing the most effective insecticides. Theoretically, insecticides shall exert their maximum killing effect on the targeted insects but yield less or no effect on other non-targeted organisms, including humans $[8,26]$. To tackle this problem, studies to investigate pharmacodynamics, pharmacokinetics, and mechanistic basis of insecticides can be performed using an insect model that has been widely known to have similar physiology as mosquitoes and other harmful insects [27]. The fruit fly Drosophila melanogaster has been suggested as a good model for this particular purpose [27].

Drosophila melanogaster has been used as a powerful insect model system to investigate various stressors (for example, pathogens, endogenous molecules, or even chemical entities) on certain important biochemical and physiological processes that are highly similar to humans [28-32]. In addition to that, D. melanogaster has also been used to address questions related to insect physiology and toxicology [33]. With physiological and genetic similarities with mosquitoes, the application of Drosophila as an insect model system has been proposed to provide a good understanding in the field of insect toxicology, including efforts to support the screening of effective insecticides [27,33]. With its long-standing history as a model organism, Drosophila offers the feasibility of cutting-edge experimental approaches that have been suggested to be difficult to perform in other insect model systems [27,34]. The discovery of several unique mutations in Drosophila that result in different types of physiological resistance against insecticides [35-39] further emphasizes the potential use of D. melanogaster in the field of insect toxicology. Following that, we carried out experiments to explore the insecticidal effect of EOSF using D. melanogaster as the insect model. In this study, we established the insecticidal effect of EOSF on D. melanogaster with the long aim to elucidate the mechanistic basis of action of EOSF chemical components and to reflect our findings to other medically important insects. 


\section{Materials and Methods}

\subsection{Sample preparation.}

Syzygium aromaticum flower was obtained from Bima Regency, West Nusa Tenggara Province (NTB), Indonesia. A total of $5 \mathrm{~kg}$ of dried samples were prepared by the water distillation method. The distillation process was carried out for 8 hours. The essential oil of Syzygium aromaticum flower (EOSF) was further processed using $1 \%$ of sodium sulfate anhydride $\left(\mathrm{Na}_{2} \mathrm{SO}_{4}\right)$ in a separating funnel and mixed for 10 minutes. A layer of $\mathrm{Na}_{2} \mathrm{SO}_{4}$ was removed and poured into a new container. The obtained EOSF was stored for further testing.

\subsection{Fly stock.}

The $w^{1118}$ Drosophila melanogaster line used in this study was generously provided by the Host and Response Laboratory of Kanazawa University, Japan. Male and female flies at the age of 4-7 days were used in the entire experiment. These flies were placed in a culture vial containing standard cornmeal-agar food and maintained in standard conditions $\left(25^{\circ} \mathrm{C}, 12\right.$ hours light cycle, and 12 hours dark cycle).

\subsection{Mortality rate assay.}

All fly groups were monitored for their mortality rates (Figure 1) based on the following procedure. Briefly, males and females of $D$. melanogaster were separately assigned into five groups. Each group consisted of ten male/female flies at the age of 4-7 days determined from their pupal case's first day of emergence. All flies were fed with standard food prior to mortality assay testing. One group of flies was exposed to $1000 \mu \mathrm{l}(13.16 \mathrm{mg} / \mathrm{ml})$ of prallethrin, a pyrethroid insecticide, and this group was designated as the positive control group. Three groups, designated as treatment groups, were subjected to EOSF exposure at different volumes: 10,100 , and $1000 \mu \mathrm{L}$. All groups were treated for 30 minutes with the assigned treatments and were subsequently transferred to separate vials containing standard fly food and maintained until the end of observation.

\subsection{Locomotor assay.}

All fly groups were monitored for locomotor (Figure 1) based on the negative geotaxis method, as previously described [40] with slight modifications. Briefly, flies at the age of 4-7 days old were separated based on their male-female orientations and were further placed in a marked empty vial, designated as the locomotor testing vial. The testing vial was placed in an upright standing position in front of a climbing wall. In this assay, the testing vial (containing flies to be tested) was firmly tapped at the start of the experiment to ensure all flies start their climbing movement from the bottom of the vial at the same time. We observed and recorded events that happened in the testing vial for up to 30 seconds to obtain the data. Flies were assigned based on their position on the climbing wall, and the data were further analyzed using a custom-made Excel spreadsheet as used in [40].

\subsection{Data processing.}

Data obtained from the mortality rate assay were visualized based on the Kaplan-Meier method and analyzed statistically using the Log-Rank approach, whereas data obtained from 
the locomotor experiments were processed and statistically analyzed by a One-Way ANOVA approach followed by post hoc analysis. Data were presented as mean \pm S.D., and $p$ values of less than 0.05 were considered significant. All data were processed and visualized using GraphPad Prism ${ }^{\circledR} 8$.

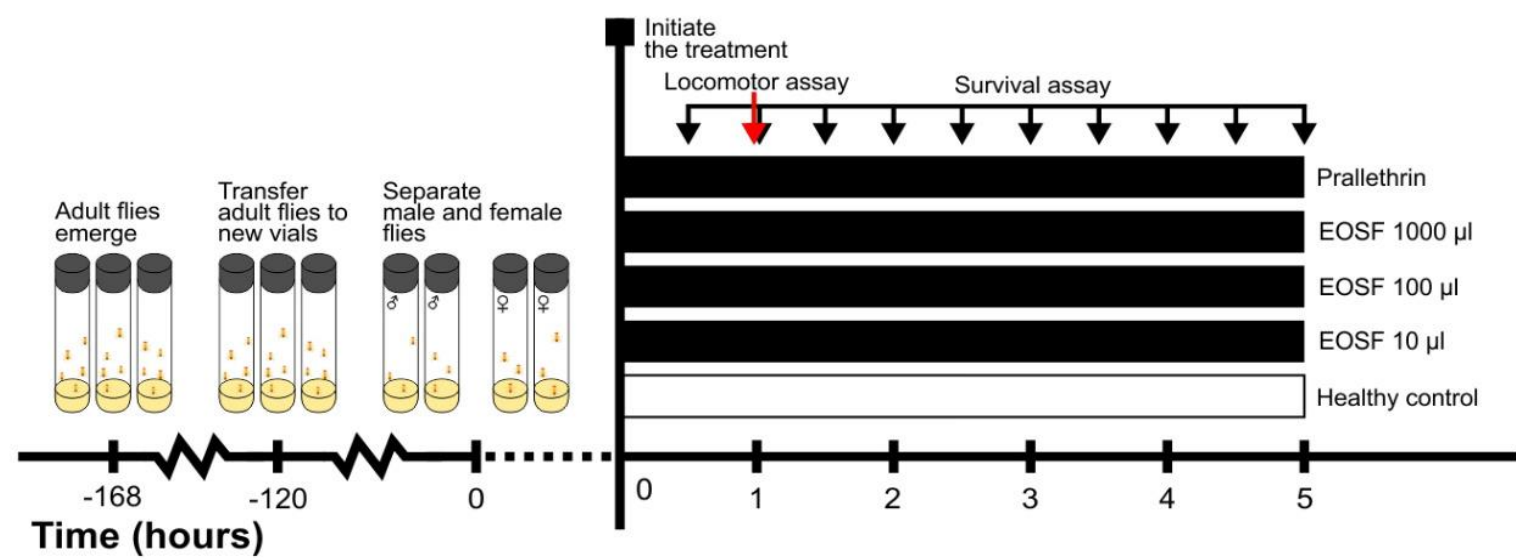

Figure 1. Experimental design was used in this study. Adult flies were prepared in vials containing standard fly food until the age of 4-7 days old and subsequently followed by male-female separation. Male and female flies were separately assigned into five different groups and tested for their locomotor activities (based on the negative geotaxis assay, red arrow) as well as their mortality rates (based on the survival assay). EOSF, essential oil of Syzygium aromaticum flower.

\section{Results and Discussion}

\subsection{Insecticidal effect of essential oil of Syzygium aromaticum flower on Drosophila.}

In general, the insecticidal effect of certain chemical entities culminates in the death of targeted insects $[8,25]$. Therefore, mortality rate assay shall serve as a simple and direct approach to investigating potential insecticidal agents' insecticidal effect. This study first carried out a mortality rate assay to determine whether EOSF can kill D. melanogaster.

A

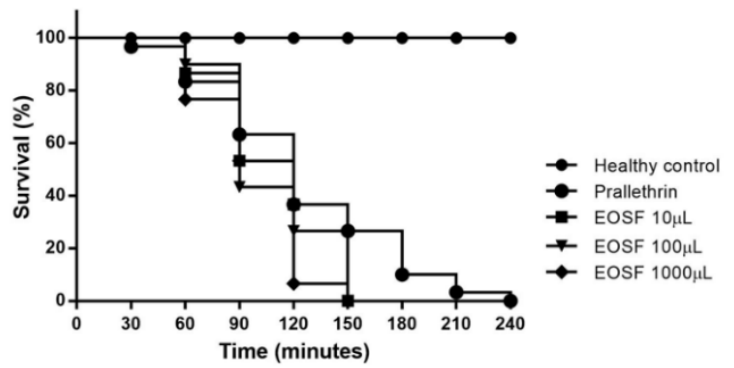

B

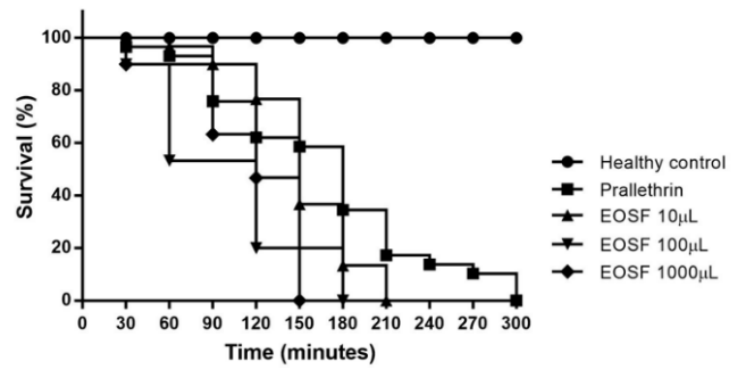

Figure 2. Mortality rate of males (A) and females (B) of w1118 D. melanogaster after exposure to the essential oil of Syzygium aromaticum flower (EOSF). Adult flies at the age of 4-7 days were divided into five groups, and the assigned groups were then exposed to either prallethrin $(13.16 \mathrm{mg}$ ) or EOSF at volumes of $10 \mu \mathrm{l}, 100 \mu \mathrm{l}$ or $1000 \mu \mathrm{l}$. One group maintained in the absence of any treatments was used as the healthy control. EOSF, essential oil of Syzygium aromaticum flower.

The assay was carried out on both males and females of D. melanogaster using three different volumes of EOSF: $10 \mu \mathrm{l}, 100 \mu \mathrm{l}$, and $1000 \mu \mathrm{l}$. Prallethrin, an insecticide of the pyrethroid group, was used as the positive control. As shown in Figure 2, continuous exposure of both males (Fig. 2A) and females (Fig. 2B) of D. melanogaster to prallethrin $(1000 \mu \mathrm{l} ; 13,15$ 
$\mathrm{mg} / \mathrm{ml}$ ) resulted in the increased mortality of flies in a dose-dependent manner, suggesting that prallethrin yielded insecticidal effect on D. melanogaster. Prallethrin stimulates insects' central nervous system activity via competitive interference with cationic conductance of nerve cells' lipid layer leading to its insecticidal effect [41], and apparently, this insecticidal effect was also evident in Drosophila. However, whether the same mechanism of action is also true in Drosophila remains an issue to be investigated.

EOSF exposure at all concentrations increased the mortality rate of male and female flies (Figure 2). However, the insecticidal effect shown by the EOSF to male Drosophila was not related to the amount of EOSF given to the tested flies. As we can see in Figure 2, male flies succumbed earlier than female flies, suggesting the possible existence of the sexdependent effect of EOSF to Drosophila. Moreover, the insecticidal effect of EOSF on the female flies occurred in a dose-dependent manner, and interestingly this trend was not observed entirely in their male counterparts. How this discrepancy occurred is not known yet, but we believe further exploration on this issue shall have its merit. Further observations of EOSF exposure showed that D. melanogaster experienced convulsions in the legs and back before dying. That is due to the possibility of competitive inhibition of the acetylcholinesterase (AChE) enzyme by the compounds contained in the EOSF, as reported in the standardized extract of Syzygium aromaticum [42]. In addition, insecticidal activity of EOSF might be achieved via mechanism(s) related to competitive interference in the activities of the dopaminergic, the cholinergic, and/or the octopaminergic system of insects [43].

\subsection{Impaired fly locomotor prior to death upon treatment with essential oil of Syzygium} aromaticum flower.

Upon exposure to exogenous substances or infection, fly locomotor is negatively impaired prior to death [44]. To examine whether such a trend was also observable in our study, we carried out a locomotor test based on the protocol of negative geotaxis assay, as described previously [40].

A

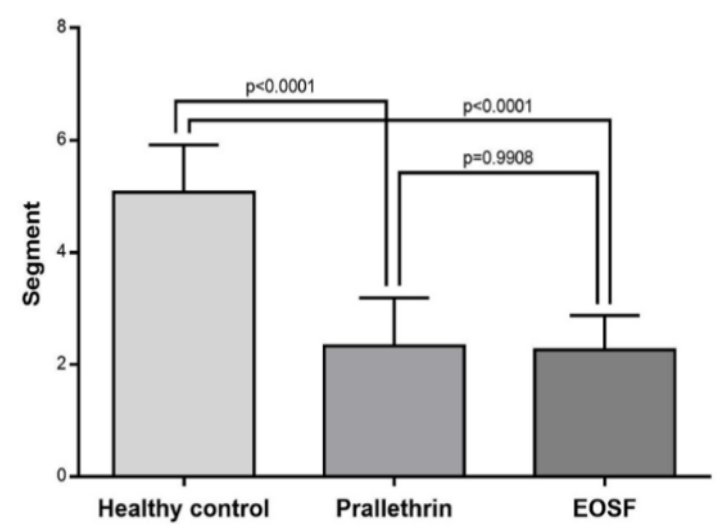

B

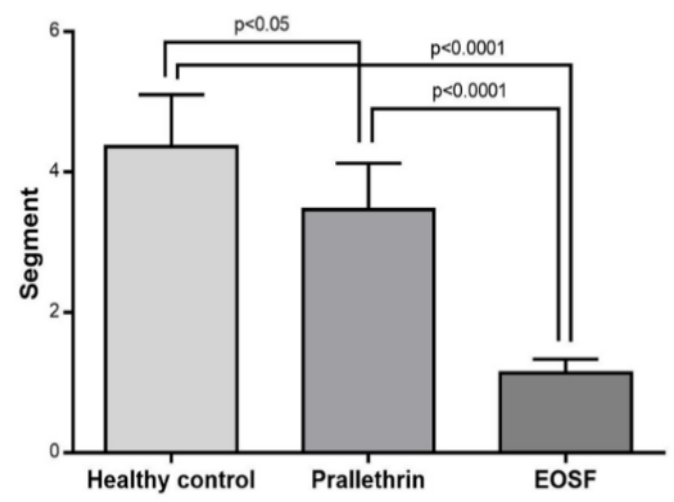

Figure 3. Locomotor of males (A) and females $(\mathbf{B})$ of $w^{1118}$ D. melanogaster after exposure to the essential oil of Syzygium aromaticum flower (EOSF). Adult flies at the age of 4-7 days were divided into three groups, and the assigned groups were then exposed to either prallethrin $(13.16 \mathrm{mg})$ or EOSF at volumes of $100 \mu \mathrm{l}$ for 30 minutes. One group maintained in the absence of any treatments was used as the healthy control. EOSF, essential oil of Syzygium aromaticum flower. 
As can be seen in Figure 3, the locomotor of both male (Figure 3A) and female (Figure 3B) flies was reduced in the presence of EOSF, further suggesting the effect of EOSF on Drosophila locomotor. Fly locomotor can be affected by alteration in the nervous system's activity in D. melanogaster [45]. Hence, it would be interesting to investigate whether ESOF can alter the activity of the fly nervous system (as well as explore potential mechanisms responsible for such events). Furthermore, based on results presented in Figure 3, it is apparent that fruit flies $D$. melanogaster experienced reduced locomotor activity after being exposed to either pralethrin and EOSF, and such a trend was evident in both males and female flies. However, a slight discrepancy in male and female flies' locomotor responses to prallethrin was observable, whereas such a trend was not seen in the EOSF-treated flies (locomotor reduction occurred almost simultaneously in male and female Drosophila upon EOSF treatment). While the reasons on why such a trend was observed remain elusive, this result might suggest the possible sex-dependent effect of prallethrin on Drosophila locomotor activity. It is tempting to speculate that such difference might occur due to differences in the targets of pralethrin and EOSF. In general, results obtained in the fruit fly D. melanogaster can provide information about insecticides' activities in three ways, such as basic understanding of insecticides mechanism of action, the mechanism of insect resistance against particular insecticides, and novel host factors (receptors or enzymes) that can be used as new targets for insecticidal compounds [27]. Considering our results were profoundly related to the phenotypical effect of EOSF on insects, it would be really interesting to explore the mode(s) of action of EOSF components using Drosophila as an insect model and whether the resultant findings are translatable to other agriculture- and medically-important insects.

\section{Conclusions}

This study demonstrated the insecticidal effect of essential oil of Syzygium aromaticum flower (EOSF) on males and females of D. melanogaster and observed impaired locomotor activity of the affected flies before death. Our findings further clarify the potential use of $D$. melanogaster to investigate insecticide candidates in the future.

\section{Funding}

This research received no external funding.

\section{Acknowledgments}

We want to offer our complete gratitude to Prof. Yoshinobu Nakanishi (Kanazawa University, Japan) for his generous support in providing the fruit fly (D. melanogaster) line used in this study.

\section{Conflicts of Interest}

We declare that we have no conflict of interest.

\section{References}

1. Stork, N.E. How Many Species of Insects and Other Terrestrial Arthropods Are There on Earth? Annual Review of Entomology 2018, 63, 31-45, https://doi.org/10.1146/annurev-ento-020117-043348.

2. Rader, R.; Bartomeus, I.; Garibaldi, L.A.; Garratt, M.P.D.; Howlett, B.G.; Winfree, R.; Cunningham, S.A.; Mayfield, M.M.; Arthur, A.D.; Andersson, G.K.S.; Bommarco, R.; Brittain, C.; Carvalheiro, L.G.; Chacoff, 
N.P.; Entling, M.H.; Foully, B.; Freitas, B.M.; Gemmill-Herren, B.; Ghazoul, J.; Griffin, S.R.; Gross, C.L.; Herbertsson, L.; Herzog, F.; Hipólito, J.; Jaggar, S.; Jauker, F.; Klein, A.-M.; Kleijn, D.; Krishnan, S.; Lemos, C.Q.; Lindström, S.A.M.; Mandelik, Y.; Monteiro, V.M.; Nelson, W.; Nilsson, L.; Pattemore, D.E.; de O. Pereira, N.; Pisanty, G.; Potts, S.G.; Reemer, M.; Rundlöf, M.; Sheffield, C.S.; Scheper, J.; Schüepp, C.; Smith, H.G.; Stanley, D.A.; Stout, J.C.; Szentgyörgyi, H.; Taki, H.; Vergara, C.H.; Viana, B.F.; Woyciechowski, M. Non-bee insects are important contributors to global crop pollination. Proceedings of the National Academy of Sciences 2016, 113, 146-151, https://doi.org/10.1073/pnas.1517092112.

3. Warren, M.S.; Maes, D.; van Swaay, C.A.M.; Goffart, P.; Van Dyck, H.; Bourn, N.A.D.; Wynhoff, I.; Hoare, D.; Ellis, S. The decline of butterflies in Europe: Problems, significance, and possible solutions. Proceedings of the National Academy of Sciences 2021, 118, e2002551117, https://doi.org/10.1073/pnas.2002551117.

4. Evans, T.A.; Kasseney, B.D. The Dominance Hierarchy of Wood-Eating Termites from China. Insects 2019 , 10, 210, https://doi.org/10.3390/insects10070210.

5. Vreysen, M.J.B.; Abd-Alla, A.M.M.; Bourtzis, K.; Bouyer, J.; Caceres, C.; de Beer, C.; Oliveira Carvalho, D.; Maiga, H.; Mamai, W.; Nikolouli, K.; Yamada, H.; Pereira, R. The Insect Pest Control Laboratory of the Joint FAO/IAEA Programme: Ten Years (2010-2020) of Research and Development, Achievements and Challenges in Support of the Sterile Insect Technique. Insects 2021, 12, 346, https://doi.org/10.3390/insects12040346.

6. Shaw, W.R.; Catteruccia, F. Vector biology meets disease control: using basic research to fight vector-borne diseases. Nature Microbiology 2019, 4, 20-34, https://doi.org/10.1038/s41564-018-0214-7.

7. Zhang, L.; Lecoq, M.; Latchininsky, A.; Hunter, D. Locust and grasshopper management. Annual Review of Entomology 2019, 64, 15-34, https://doi.org/0.1146/annurev-ento-011118-112500.

8. Wojciechowska, M.; Stepnowski, P.; Gołębiowski, M. The use of insecticides to control insect pests. $\begin{array}{lllll}\text { Invertebrate } \quad \text { Survival } & \text { Journal } & \text { 210-220, }\end{array}$ https://www.researchgate.net/publication/306191667_The_use_of_insecticides_to_control_insect_pests.

9. Tlak Gajger, I.; Dar, S.A. Plant Allelochemicals as Sources of Insecticides. Insects 2021, 12, 189, https://doi.org/390/insects12030189.

10. Carvalho, F.P. Pesticides, environment, and food safety. Food and Energy Security 2017, 6, 48-60, https://doi.org/10.1002/fes3.108.

11. Mossa, A.-T.H.; Mohafrash, S.M.M.; Chandrasekaran, N. Safety of natural insecticides: Toxic effects on experimental animals. BioMed Research International 2018, 2018, 4308054 , https://doi.org/10.1155/2018/4308054.

12. Dambolena, J.S.; Zunino, M.P.; Herrera, J.M.; Pizzolitto, R.P.; Areco, V.A.; Zygadlo, J.A. Terpenes: Natural products for controlling insects of importance to human health-A structure-activity relationship study. Psyche 2016, 2016, 4595823, https://doi.org/10.1155/2016/4595823.

13. Abdelatti, Z.A.S.; Hartbauer, M. Plant oil mixtures as a novel botanical pesticide to control gregarious locusts. Journal of Pest Science 2020, 93, 341-353, https://doi.org/10.1007/s10340-019-01169-7.

14. Senthil-Nathan, S. A Review of Resistance Mechanisms of Synthetic Insecticides and Botanicals, Phytochemicals, and Essential Oils as Alternative Larvicidal Agents Against Mosquitoes. Frontiers in Physiology 2020, 10, https://doi.org/10.3389/fphys.2019.01591.

15. Isman, M.B. Botanical Insecticides in the Twenty-First Century-Fulfilling Their Promise? Annual Review of Entomology 2020, 65, 233-249, https://doi.org/10.1146/annurev-ento-011019-025010.

16. Batiha, G.E.-S.; Alkazmi, L.M.; Wasef, L.G.; Beshbishy, A.M.; Nadwa, E.H.; Rashwan, E.K. Syzygium aromaticum L. (Myrtaceae): Traditional Uses, Bioactive Chemical Constituents, Pharmacological and Toxicological Activities. Biomolecules 2020, 10, 202, https://doi.org/10.3390/biom10020202.

17. Fernandes, M.J.G.; Pereira, R.B.; Pereira, D.M.; Fortes, A.G.; Castanheira, E.M.S.; Gonçalves, M.S.T. New Eugenol Derivatives with Enhanced Insecticidal Activity. International Journal of Molecular Sciences 2020, 21, 9257, https://doi.org/10.3390/ijms21239257.

18. Barbosa, J.D.; Silva, V.B.; Alves, P.B.; Gumina, G.; Santos, R.L.; Sousa, D.P.; Cavalcanti, S.C. Structureactivity relationships of eugenol derivatives against Aedes aegypti (Diptera: Culicidae) larvae. Pest Manag Sci 2012, 68, 1478-1483, https://doi.org/10.1002/ps.3331.

19. Prates, L.H.F.; Faroni, L.R.D.A.; Heleno, F.F.; de Queiroz, M.E.L.R.; de Sousa, A.H.; Silva, M.V.d.A. Eugenol diffusion coefficient and its potential to control Sitophilus zeamais in rice. Scientific Reports 2019, 9, 11161, https://doi.org/10.1038/s41598-019-47562-1. 
20. Park, I.K.; Shin, S.C. Fumigant activity of plant essential oils and components from garlic (Allium sativum) and clove bud (Eugenia caryophyllata) oils against the Japanese termite (Reticulitermes speratus Kolbe). $J$ Agric Food Chem 2005, 53, 4388-4392, https://doi.org/10.1021/jf050393r.

21. Mapossa, A.B.; Focke, W.W.; Tewo, R.K.; Androsch, R.; Kruger, T. Mosquito-repellent controlled-release formulations for fighting infectious diseases. Malaria Journal 2021, 20, 165, https://doi.org/10.1186/s12936021-03681-7.

22. Mwingira, V.; Mboera, L.E.G.; Dicke, M.; Takken, W. Exploiting the chemical ecology of mosquito oviposition behavior in mosquito surveillance and control: a review. Journal of Vector Ecology 2020, 45, 155-179, https://doi.org/https://doi.org/10.1111/jvec.12387.

23. Bicchi, C.; Joulain, D. Techniques for preparing essential oils and aromatic extracts. Flavour and Fragrance Journal 2018, 33, 133-134, https://doi.org/10.1002/ffj.3433.

24. Isman, M.B.; Miresmailli, S.; Machial, C. Commercial opportunities for pesticides based on plant essential oils in agriculture, industry and consumer products. Phytochemistry Reviews 2011, 10, 197-204, https://doi.org/10.1007/s11101-010-9170-4.

25. Sparks, T.C.; Crossthwaite, A.J.; Nauen, R.; Banba, S.; Cordova, D.; Earley, F.; Ebbinghaus-Kintscher, U.; Fujioka, S.; Hirao, A.; Karmon, D.; Kennedy, R.; Nakao, T.; Popham, H.J.R.; Salgado, V.; Watson, G.B.; Wedel, B.J.; Wessels, F.J. Insecticides, biologics and nematicides: Updates to IRAC's mode of action classification - a tool for resistance management. Pesticide Biochemistry and Physiology 2020, 167, 104587, https://doi.org/10.1016/j.pestbp.2020.104587.

26. Coats, J.R. Insecticide Mode of Action; Elsevier Science: 2012, https://www.elsevier.com/books/insecticidemode-of-action/coats/978-0-12-177120-1.

27. Schneider, D. Using Drosophila as a model insect. Nat Rev Genet 2000, 1, 218-226, https://doi.org/10.1038/35042080.

28. Ugur, B.; Chen, K.; Bellen, H.J. Drosophila tools and assays for the study of human diseases. Dis Model Mech 2016, 9, 235-244, https://doi.org/10.1242/dmm.023762.

29. Nainu, F.; Shiratsuchi, A.; Nakanishi, Y. Induction of apoptosis and subsequent phagocytosis of virusinfected cells as an antiviral mechanism. Frontiers in immunology 2017, 8, 1220-1220, https://doi.org/10.3389/fimmu.2017.01220.

30. Asri, R.M.; Salim, E.; Nainu, F.; Hori, A.; Kuraishi, T. Sterile induction of innate immunity in Drosophila melanogaster. Frontiers in Bioscience (Landmark Edition) 2019, 24, 1390-1400, https://doi.org/10.2741/4786.

31. Rahmatika, D.; Kuroda, N.; Min, Z.; Nainu, F.; Nagaosa, K.; Nakanishi, Y. Inhibitory effects of viral infection on cancer development. Virology 2019, 528, 48-53, https://doi.org/10.1016/j.virol.2018.12.008.

32. Nainu, F.; Salim, E.; Asri, R.M.; Hori, A.; Kuraishi, T. Neurodegenerative disorders and sterile inflammation: lessons from a Drosophila model. The Journal of Biochemistry 2019, 166, 213-221, https://doi.org/10.1093/jb/mvz053.

33. Scott, J.G.; Buchon, N. Drosophila melanogaster as a powerful tool for studying insect toxicology. Pesticide Biochemistry and Physiology 2019, 161, 95-103, https://doi.org/10.1016/j.pestbp.2019.09.006.

34. Nainu, F.; Nakanishi, Y.; Shiratsuchi, A. Fruit fly as a model organism in the study of human diseases and drug discovery. Journal of Center for Medical Education Sapporo Medical University 2019, 21-32, https://doi.org/10.15114/jcme.10.21.

35. Pedra, J.H.; McIntyre, L.M.; Scharf, M.E.; Pittendrigh, B.R. Genome-wide transcription profile of field- and laboratory-selected dichlorodiphenyltrichloroethane (DDT)-resistant Drosophila. Proc Natl Acad Sci USA 2004, 101, 7034-7039, https://doi.org/10.1073/pnas.0400580101.

36. Ffrench-Constant, R.H.; Rocheleau, T.A.; Steichen, J.C.; Chalmers, A.E. A point mutation in a Drosophila GABA receptor confers insecticide resistance. Nature 1993, 363, 449-451, https://doi.org/10.1038/363449a0.

37. Martin, R.L.; Pittendrigh, B.; Liu, J.; Reenan, R.; ffrench-Constant, R.; Hanck, D.A. Point mutations in domain III of a Drosophila neuronal Na channel confer resistance to allethrin. Insect Biochem Mol Biol 2000, 30, 1051-1059, https://doi.org/10.1016/s0965-1748(00)00080-1.

38. Homem, R.A.; Buttery, B.; Richardson, E.; Tan, Y.; Field, L.M.; Williamson, M.S.; Emyr Davies, T.G. Evolutionary trade-offs of insecticide resistance - The fitness costs associated with target-site mutations in the nAChR of Drosophila melanogaster. Molecular Ecology 2020, 29, 2661-2675, https://doi.org/10.1111/mec.15503.

39. Perry, T.; Chen, W.; Ghazali, R.; Yang, Y.T.; Christesen, D.; Martelli, F.; Lumb, C.; Bao Luong, H.N.; Mitchell, J.; Holien, J.K.; Parker, M.W.; Sparks, T.C.; Batterham, P. Role of nicotinic acetylcholine receptor 
subunits in the mode of action of neonicotinoid, sulfoximine and spinosyn insecticides in Drosophila melanogaster. Insect Biochemistry and Molecular Biology 2021, 131, 103547, https://doi.org/10.1016/j.ibmb.2021.103547.

40. Strangward, P.; Alnuamaani, C.; Patel, S.; Prokop, A. Lesson 1 - The climbing assay: Learning data analysis through live experiments with fruit flies. https://droso4schools.wordpress.com/12-climbing-assay/.

41. Soderlund, D.M.; Krieger, R.; Chapter 77 - Toxicology and Mode of Action of Pyrethroid Insecticides. In Hayes' Handbook of Pesticide Toxicology (Third Edition).Ed. Academic Press: New York 2010, 1665-1686. https://www.elsevier.com/books/hayes-handbook-of-pesticide-toxicology/krieger/978-0-08-092201-0.

42. Dalai, M.K.; Bhadra, S.; Chaudhary, S.K.; Bandyopadhyay, A.; Mukherjee, P.K. Anti-cholinesterase activity of the standardized extract of Syzygium aromaticum L. Pharmacognosy magazine 2014, 10, S276-S282, https://doi.org/10.4103/0973-1296.133275.

43. Isman, M.B. Botanical insecticides, deterrents, and repellents in modern agriculture and an increasingly regulated world. Annual Review of Entomology 2006, 51, 45-66, https://doi.org/10.1146/annurev.ento.51.110104.151146.

44. Linderman, J.A.; Chambers, M.C.; Gupta, A.S.; Schneider, D.S. Infection-related declines in chill coma recovery and negative geotaxis in Drosophila melanogaster. PLOS ONE 2012, 7, e41907, https://doi.org/10.1371/journal.pone.0041907.

45. Sun, J.; Xu, A.Q.; Giraud, J.; Poppinga, H.; Riemensperger, T.; Fiala, A.; Birman, S. Neural control of startleinduced locomotion by the mushroom bodies and associated neurons in Drosophila. Frontiers in systems neuroscience 2018, 12, 6-6, https://doi.org/10.3389/fnsys.2018.00006. 